\title{
Rapid metabolic profiling of Nicotiana tabacum defence responses against Phytophthora nicotianae using direct infrared laser desorption ionization mass spectrometry and principal component analysis
}

Alfredo J Ibáñez', Judith Scharte², Philipp Bones², Alexander Pirkl1', Stefan Meldau³, Ian T Baldwin³, Franz Hillenkamp', Engelbert Weis ${ }^{2}$ and Klaus Dreisewerd*1

\begin{abstract}
Background: Successful defence of tobacco plants against attack from the oomycete Phytophthora nicotianae includes a type of local programmed cell death called the hypersensitive response. Complex and not completely understood signaling processes are required to mediate the development of this defence in the infected tissue. Here, we demonstrate that different families of metabolites can be monitored in small pieces of infected, mechanically-stressed, and healthy tobacco leaves using direct infrared laser desorption ionization orthogonal time-of-flight mass spectrometry. The defence response was monitored for 1 - 9 hours post infection.

Results: Infrared laser desorption ionization orthogonal time-of-flight mass spectrometry allows rapid and simultaneous detection in both negative and positive ion mode of a wide range of naturally occurring primary and secondary metabolites. An unsupervised principal component analysis was employed to identify correlations between changes in metabolite expression (obtained at different times and sample treatment conditions) and the overall defence response.

A one-dimensional projection of the principal components 1 and 2 obtained from positive ion mode spectra was used to generate a Biological Response Index (BRI). The BRI obtained for each sample treatment was compared with the number of dead cells found in the respective tissue. The high correlation between these two values suggested that the $\mathrm{BRI}$ provides a rapid assessment of the plant response against the pathogen infection. Evaluation of the loading plots of the principal components ( 1 and 2 ) reveals a correlation among three metabolic cascades and the defence response generated in infected leaves. Analysis of selected phytohormones by liquid chromatography electrospray ionization mass spectrometry verified our findings.
\end{abstract}

Conclusion: The described methodology allows for rapid assessment of infection-specific changes in the plant metabolism, in particular of phenolics, alkaloids, oxylipins, and carbohydrates. Moreover, potential novel biomarkers can be detected and used to predict the quality of plant infections.

\section{Background}

Metabolism consists of a complex network of biosynthetic pathways and comprises a series of biochemical

* Correspondence: dreisew@uni-muenster.de

1 Institute of Medical Physics and Biophysics, Westfälische Wilhelms-Universität Münster, Robert-Koch-Str. 31, D-48149 Münster, Germany

Full list of author information is available at the end of the article reactions that are catalyzed by enzymes [1,2]. Plants and animals produce a remarkably diverse array of over 100,000 secondary metabolites. In contrast to the primary metabolites, secondary metabolites are normally not directly involved in growth, development, and reproduction, but partly play essential roles in the adaptation of the organisms to their environments [1-5]. The rich 
diversity of secondary metabolites results from a co-evolutionary process with biotic attackers. Secondary metabolites stored in various plant organs and cell compartments play important roles as constitutive defence against herbivores and microbial pathogens. Natural selection favors those plants that have developed distinct cellular defence responses, specifically induced and tailored against the invasion of pathogens or attack by insects [1-5]. Induced defences against various attackers are differentially orchestrated by a network of interacting signaling pathways.

Depending on the signaling pathway employed, the defence response may in some cases only encompass the infected tissue (local response) or in addition involve noninfected parts of the plant (systemic response), thus protecting the plant against subsequent attacks [6,7]. The phytohormone salicylic acid (SA) is mainly induced by biotrophic and hemi-biotrophic parasites and initiates and controls both the systemic response and the hypersensitive response (HR) [5,8-10]. The HR is a type of programmed cell death in which the plant sacrifices a few cells immediately surrounding the attacked cell, thereby restricting pathogen growth [8-10]. For the proper development of a HR, the SA-signaling pathway includes feedback loops which integrate other defence-associated signals, such as (i) jasmonic acid (JA) [11,12], (ii) ethylene (ET) [13], and (iii) nitric oxide (NO) [14-16]. Other metabolic events, which are important in the execution of HR include reinforcement of the cell wall [17], phytoalexin production [18], expression of pathogenesis-related proteins [19], reactive oxygen species (ROS) generation $[17,20]$, and the readjustment of the primary metabolism, that includes sugar accumulation and signaling $[17,20]$. The overall signature of the complex metabolic and signaling networks in the plant determines the pattern of defence-related metabolome changes and, hence, eventually the outcome of the plant - pathogen interaction $[1,8,9,12]$.

Different methods have been developed for the analysis of multiple metabolites during the plant defence response, such as fluorescence microscopy [21-24] and mass spectrometry (MS) [25-30] Because of the high complexity of the plant metabolome, hyphenated MSbased methods are mostly preferred, e.g. the coupling of a mass spectrometer with gas chromatography (GC) [2527] or liquid chromatography (LC) [28-30]. By adding reference compounds, these techniques allow the absolute quantification of individual metabolites [27-30]; however, the employment of these hyphenated methods requires cumbersome sample preparation processes [25-30].

Matrix-assisted laser desorption ionization mass spectrometry (MALDI MS) has been increasingly employed in metabolomic studies. Advantages of this analytical method are that first limited effort is required for sample preparation and second the method lends itself to high throughput analysis [31-35]. A few reports have described the utilization of ultraviolet (UV) and infrared (IR) lasers for the analysis of plant metabolites directly from tissue [32,36-40]. This is possible because laser energy in the UV or IR region can be absorbed directly by different biomolecules in the tissue. If the concentration of absorbing biomolecules is high enough, they can function as an endogenous matrix for the MALDI process. IR lasers with an emission wavelength around $3 \mu \mathrm{m}$, such as an Er:YAG laser emitting at $2.94 \mu \mathrm{m}$ or an optical parametric oscillator (OPO) laser, make use of O-H containing biomolecules (i.e. mostly water molecules) as an endogenous matrix via excitation of the $\mathrm{O}-\mathrm{H}$ bond stretch vibrations [41]. In the following, we will use the abbreviation "IR-LDI" instead of "IR-MALDI" to account for the fact that only endogenous biomolecules are used as energy absorbers.

While direct tissue analysis by mass spectrometry generally does not allow for absolute quantification of molecular concentrations, a semi-quantitative analysis may be possible by recording the changes in signal intensities of individual compounds, for instance in response to a treatment. A particularly elegant method to retrieve information about even small changes of the molecular profiles in a complex system (a LDI mass spectrum may contain hundreds of ion signals) is the use of principal component analysis (PCA) [42,43]. PCA is a multivariate data analysis which can be used to reduce the complexity of large amounts of detectable ion signals to a small number of independent (orthogonal) component vectors. Hence, in the PCA the individual identity as well as the absolute intensity of an ion signal are not as relevant as the mass spectral profile as a whole $[42,43]$.

With respect to the mass analyzer, for the analysis of rough and electrically non-conducting surfaces (such as leaf tissue), orthogonal time-of-flight (oTOF) mass spectrometers have been found to provide particularly beneficial properties $[40,44,45]$. This is because these instruments decouple the ion formation process from the time-of-flight measurement and thereby provide a high and constant mass accuracy, independent of the exact morphology of the investigated sample $[40,44,45]$. The combination of IR-LDI and oTOF MS also provides particularly soft desorption/ionization conditions that produce a minimum of analyte ion dissociation $[44,46]$. The analysis of a wide range of metabolites directly from plant tissues - e.g. lipids (phospholipids, sulfates, triglycerides), carbohydrates (oligosaccharides), glycosidic flavonoids, and alkaloids - has been reported using this type of instrument [40].

Here, we used direct IR-LDI-oTOF mass spectrometry to simultaneously profile a large number of metabolites of the tobacco plant Nicotiana tabacum (Samsun, SNN), 
generated during development ( 1 to 9 hours post infection) of the HR against the oomycete Phytophthora nicotianae. A multivariate analysis - principal component analysis (PCA) - was used to reduce the large and complex LDI MS data to one- or two- dimensional data sets. The statistical analysis was compared with an established indicator of the biological response of the plant - pathogen system, dead cell count analysis, and an established method for studying plant defence responses, i.e. quantification of defence-related phytohormones using liquid chromatography in combination with electrospray ionization tandem mass spectrometry (LC-ESI MS/MS) [2830]. We conclude that IR-LDI MS metabolome profiling in conjunction with PCA can be a powerful tool to obtain information about plant defence cascades and to monitor the intensity and progression of the infection processes.

\section{Results and Discussion}

Although extensive data exists describing the role of various secondary metabolites (such as SA) during the hypersensitive defence response in pathogen-plant interaction [5,8-12], much remains to be learned about the response as a whole.

In a classical approach, it would be possible to identify the different signal cascades that are activated in the leaf during the infection by quantifying "key" metabolites for each sample treatment conditions (i.e. blank, placebo, and infection). However to reliably quantify these compounds, an internal standard would be required for each metabolite of interest to compensate for the matrix effects that originate from the inherent amount of variability associated with biological samples. Thus, the quantification approach is suitable for the verification of a hypothesis but is not recommended as the first step for any plant study when not much is known about the occurring cellular processes, as it is the case here.

Relative up- or down-regulation of metabolic cascades may be followed by employing a semi-quantitative approach. Here, we applied this method and used the earliest measurement time point obtained for each sample treatment (i.e. $1 \mathrm{hpi}$ ) as reference point. This way, we can compensate for non-biological effects (e.g. systemic analytical errors caused by changes in the growth environment) which could influence the metabolic response. The general procedure and experimental workflow of the analysis is depicted in Figure 1; see Materials and Methods for details.

The accessible mass range of the matrix-less LDI MS approach is limited to about $1000 \mathrm{~m} / z$ units. Because no matrix was employed in these measurements, the mass spectra are fully devoid of the matrix-derived chemical background, which can severely complicate standard MALDI MS analysis of small molecules. Moreover, signals corresponding to other relative abundant biological substances - such as peptides - also are not produced. The IR-LDI-oTOF MS measurements were performed in both positive and negative ion modes from differently treated leaf samples: zoospores infiltrated (infected, I), tap-water infiltrated (placebo, P) and untreated (blank, B), and at time points of $1,3,6$, and 9 hpi (see Material and Methods for details on the sample preparation procedure). As an example, Additional file 1 shows the positive and negative ion mode mass spectra for the region between $\mathrm{m} / z 100$ to 500 obtained using IR-LDI-oTOF MS for two samples, infected $\left(\mathrm{I}_{\mathrm{P}}\right)$ and placebo $\left(\mathrm{P}_{\mathrm{I}}\right)$, harvested at 6 hpi from a $S N N$ tobacco leaf. A full list of all consistently detected ions is provided in Table 1.

Figure 2 displays the time-profiles for a subset of 9 example metabolites, as derived from the IR-LDI MS analysis of differently treated samples; data are normalized to the signal intensity obtained at $1 \mathrm{hpi}$. The chemical assignments (identities) for these 9 metabolites and several other compounds (Table 1) could be made with reasonable confidence on the basis of precise mass measurement, the isotope ratios of the corresponding signals, and metabolic databases (see Material and Methods for details on the identification of metabolites).

\section{Alkaloids and phenolics}

The alkaloid tetrahydrobiopterin (THB, Figure 2A) was identified as a metabolite for which the concentration increases substantially exclusively during local infection. THB functions as redox-cofactor for a number of metabolic processes (e.g. the oxidation of phenylalanine). In animals, it is also a cofactor of nitric oxide synthase (NOs) [47], but the exact plant metabolism of NO, an important messenger in stress response, is still controversial [48]. Spermidine (Figure 2B) a polyamine involved in various cellular processes [49], exhibits a moderate transient concentration increase (at $\sim 3 \mathrm{hpi}$ ) in infected samples, but due to its multiple functions in plant metabolism it cannot be regarded a key indicator of infection. In contrast, nicotine levels (and possibly also those of its isomer anabasine) significantly decrease in infected leaf samples (Figure 2C). The alkaloid nicotine, a highly effective insecticide, is produced in the tobacco roots, transported to leaves, and stored in vacuoles. Increase of nicotine concentration in tobacco leaves has been related to the JA signaling cascade in response to attack from herbivores $[4,29,50]$. However, in contrast to the response to herbivore attack, infection with Phytophthora nicotianae results in a steep decline in nicotine concentration, when compared to placebo and blank samples. This metabolic change might be correlated with an increase in SA levels, an antagonist of JA (see hormone analysis below; Figure 3 ).

Phenolic metabolites whose biosynthesis is derived from the shikimic acid pathway $[1,51]$, exhibit an increase 


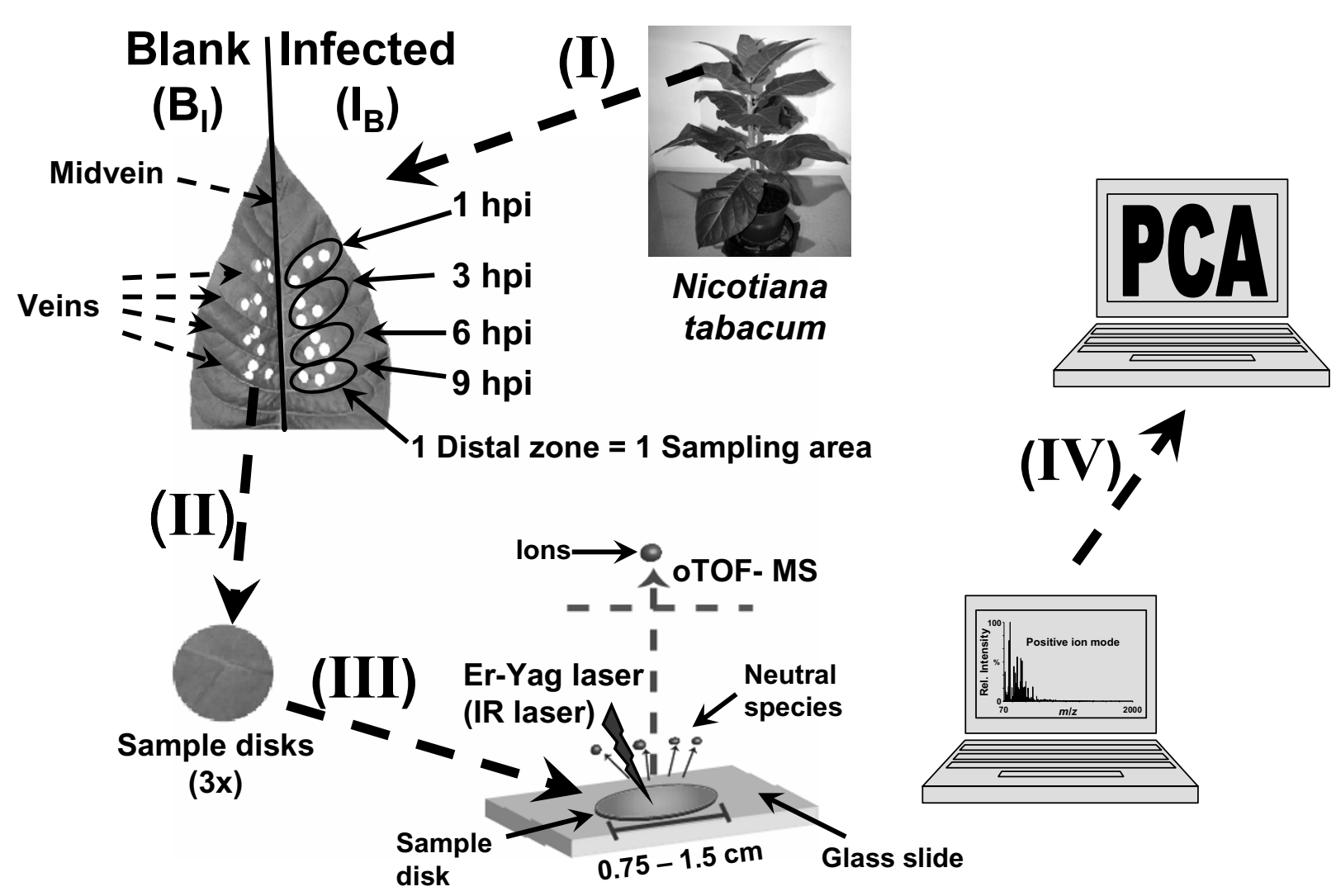

Figure 1 Workflow of the combined IR-LDI mass spectrometry - principal component analysis of plant metabolites. Schematic workflow of the analysis: (I) sample treatment, (II) sample collection, (III) direct IR-LDI-oTOF MS measurement, (IV) principal component analysis. The lower cuticle of the leaf is removed using adhesive tape and disks are placed upside down on a glass slide. The glass slide is mounted in a custom-made sample plate holder and transferred into the laser mass spectrometer for measurement. The nomenclature employed to identify the sample type is explained in the text.

in concentration during infection. Examples are two decarboxylation products of phenylalanine: tyramine (Figure 2D) and phenylethylamine (data not shown); chorismic acid (data not shown), a product of the shikimic pathway and major precursor of plant phenolics; and chlorogenic acid (data not shown), a derivative of coumaric acid. These observations concur with studies reporting a substantial up-regulation of the oxidative pentose-phosphate (OPP) pathway, which creates precursors for the shikimic pathway, and the L-phenylalanineammonia-lyase (PAL) activity, a major control step of the phenolic metabolism [17]. Chorismic acid or/and cinnamic acid (the product of the PAL reaction) are potential precursors of the hormone SA [1]. SA levels strongly increase after infection with $P$. nicotianae (Figure 3; see hormone analysis below).

\section{Free fatty acids and oxylipins}

Concentrations of free fatty acids (FAs) in plant tissues, such as $\gamma$-linolenic acid ( $\gamma$-LA, Figure $2 \mathrm{E}), \alpha$-linolenic acid (data not shown), and palmitic acid (data not shown), can be altered by wounding or infection [52-55]. For example, various oxylipins which function as stress messengers $[52,54,55]$ are created by non-enzymatical or enzymatical (lipoxygenases) oxidation of FAs, in particular $\gamma$-LA [5660]. Using IR-LDI-oTOF MS, three oxylipins were detected: peroxidated $\gamma$-linolenic acid (HOO- $\gamma$-LA, Figure 2F), peroxidated methyl- $\gamma$-linolenate (data not shown), and possibly peroxidated chloride-methyl- $\alpha$-linolenate (data not shown); all are presumably derived from $\gamma$-LA $[52,60]$. High levels of LA's, in particular of $\gamma$-LA (Figure 2E), are only observed in pathogen-infected samples and may reflect activation of phospholipases. For example, phospholipase A2 $\left(\mathrm{PLA}_{2}\right)$ is known to be activated in plants by infection [61] and constitutes the first step in the biosynthesis of the hormone JA. Increased levels of JA are indeed transiently found in infected samples at $1 \mathrm{hpi}$ (see below; Figure 3). The decrease in HOO- $\gamma$-LA (Figure 2F) and JA abundances (while $\gamma$-LA increases) in locally and not-locally infected samples, which were not under mechanical-stress (such as $B_{I}$ samples), most likely reflects the infection - induced inhibition of pathways 


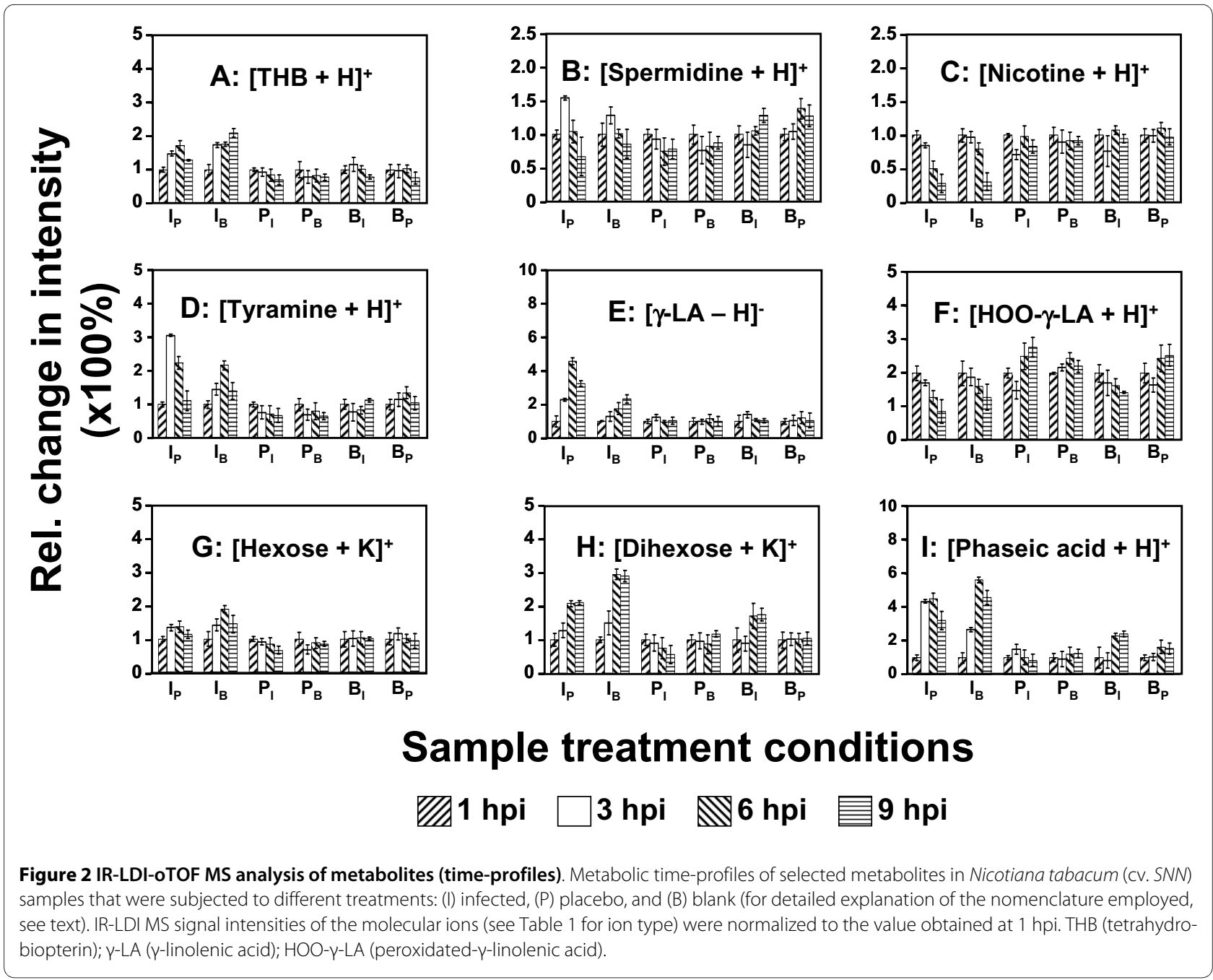

employed for lipid oxidation. This assumption is supported by the fact that the decrease in oxylipins and JA levels was not observed in samples that experience pure local mechanical-stress (which is known to activate the JA pathway). Moreover, the SA signaling cascade has been reported to block the first step in the lipoxygenase (LOX) cascade, which is responsible for the biosynthesis of JA from its precursor $\gamma$-LA $[8,52]$.

\section{Carbohydrates}

Recently, it was demonstrated for the tobacco - Phytophthora system that during development of the HR sugars (hexoses and dihexoses) accumulate in the cell wall $[17,20]$. Using IR-LDI oTOF MS, hexoses and dihexoses are detected in both positive and negative ionization modes. The time profiles of the potassiated sugar molecules are shown in Figure $2 \mathrm{G} \& 2 \mathrm{H}$, respectively. Although isomers cannot be differentiated in the MS profile, glucose and fructose are expected to comprise the major hexoses and sucrose the major dihexose in plants. In agreement with earlier biochemical analysis [17], the
MS analysis indicates a significant increase in sugar levels (in particular for the dihexose) in infected samples.

\section{Plant hormones}

ABA, a regulator of various environmental stress responses [62-64], positively affects the early (pre-invasion) defence [65]. It also influences the effect of the volatile hormone ET (which regulates the antagonistic signaling cascades of SA and JA) [66], and inhibits late defence reactions (such as the SA-mediated HR) [67]. The levels of phaseic acid (Figure 2I), the first stable decomposition product of ABA $[68,69]$, increased exclusively in the infected samples, reflecting the possible degradation of ABA (see below, Figure 3)

Because IR-LDI MS ion signals of SA, JA, and ABA were either too low in intensity (SA) or not detectable (JA, ABA), we extracted these hormones from the plant lamina and used ESI-LC MS/MS to determine their absolute concentration in tissue [28-30]. The metabolic time profiles of the three hormones are displayed in Figure 3. The figure includes data obtained from two different cul- 
Table 1: List of ion signals detected by direct IR-LDI-oTOF mass spectrometry in leaf samples of Nicotiana tabacum in (A) positive and (B) negative ion mode.*

\begin{tabular}{|c|c|c|c|c|c|}
\hline \multicolumn{6}{|c|}{ A: Positive ion mode } \\
\hline$\#$ & Obs. Mass ( $m / z)$ & Chemical Formula & Theor. Mass ( $m / z)$ & $\Delta \mathrm{m}(\mathrm{ppm})$ & Tentative Assignment* \\
\hline a1 & 104.107 & 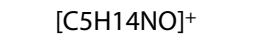 & 104.107 & 0.0 & choline \\
\hline a2 & 122.095 & {$[\mathrm{C} 8 \mathrm{H} 11 \mathrm{~N}+\mathrm{H}]^{+}$} & 122.097 & 16.4 & phenethylamine \\
\hline a3 & 132.112 & {$[\mathrm{C} 5 \mathrm{H} 13 \mathrm{~N} 3 \mathrm{O}+\mathrm{H}]^{+}$} & 132.113 & 7.6 & N-carbamoylputrescine \\
\hline a4 & 138.091 & {$[\mathrm{C} 8 \mathrm{H} 11 \mathrm{NO}+\mathrm{H}]^{+}$} & 138.092 & 7.2 & tyramine \\
\hline a5 & 146.167 & {$[\mathrm{C} 7 \mathrm{H} 19 \mathrm{~N} 3+\mathrm{H}]^{+}$} & 146.165 & 13.7 & spermidine \\
\hline a6 & 163.122 & {$[\mathrm{C} 10 \mathrm{H} 14 \mathrm{~N} 2+\mathrm{H}]^{+}$} & 163.123 & 6.1 & nicotine or anabasine \\
\hline a7 & 192.172 & {$[\mathrm{C} 13 \mathrm{H} 21 \mathrm{~N}+\mathrm{H}]^{+}$} & 192.175 & 15.6 & \\
\hline a8 & 219.027 & {$[\mathrm{C} 6 \mathrm{H} 12 \mathrm{O} 6+\mathrm{K}]^{+}$} & 219.027 & 0.0 & hexose \\
\hline a9 & 242.126 & {$[\mathrm{C} 9 \mathrm{H} 15 \mathrm{~N} 5 \mathrm{O} 3+\mathrm{H}]^{+}$} & 242.125 & 4.1 & tetrahydrobiopterin \\
\hline a10 & 251.221 & {$[\mathrm{C} 14 \mathrm{H} 26 \mathrm{~N} 4+\mathrm{H}]^{+}$} & 251.223 & 8.0 & \\
\hline a11 & 266.185 & {$[\mathrm{C} 17 \mathrm{H} 25 \mathrm{~N}+\mathrm{H}]^{+}$} & 266.186 & 3.8 & \\
\hline a12 & 269.170 & {$[\mathrm{C} 17 \mathrm{H} 2 \mathrm{ON} 2 \mathrm{O}+\mathrm{H}]^{+}$} & 269.165 & 15.8 & \\
\hline a13 & 281.140 & {$[\mathrm{C} 15 \mathrm{H} 20 \mathrm{O} 5+\mathrm{H}]^{+}$} & 281.138 & 6.0 & phaseic acid \\
\hline a14 & 311.221 & {$[\mathrm{C} 18 \mathrm{H} 30 \mathrm{O} 4+\mathrm{H}]^{+}$} & 311.221 & 0.0 & hydroperoxyoctadecatrienoic acid \\
\hline a15 & 318.153 & {$[\mathrm{C} 14 \mathrm{H} 23 \mathrm{NO} 7+\mathrm{H}]^{+}$} & 318.155 & 6.3 & glycosylated-retronecin or [tyramine + hexose $^{1}$ \\
\hline a16 & 325.236 & {$[\mathrm{C} 19 \mathrm{H} 32 \mathrm{O} 4+\mathrm{H}]^{+}$} & 325.237 & 3.1 & methyl-hydroperoxyoctadecatrienoate \\
\hline a17 & 343.186 & {$[\mathrm{C} 19 \mathrm{H} 28 \mathrm{O} 4+\mathrm{Na}]^{+}$} & 343.189 & 8.7 & \\
\hline a18 & 355.153 & {$[\mathrm{C} 19 \mathrm{H} 24 \mathrm{O} 5+\mathrm{Na}]^{+}$} & 355.152 & 2.8 & gibberellin 20 \\
\hline a19 & 361.211 & {$[\mathrm{C} 19 \mathrm{H} 33 \mathrm{ClO} 4+\mathrm{H}]^{+}$} & 361.215 & 10.0 & methyl-chloro-hydroperoxyoctadecatrienoate \\
\hline a20 & 381.079 & {$[\mathrm{C} 12 \mathrm{H} 22 \mathrm{O} 11+\mathrm{K}]^{+}$} & 381.080 & 2.6 & dihexose \\
\hline a21 & 399.085 & {$[\mathrm{C} 12 \mathrm{H} 24 \mathrm{O} 12+\mathrm{K}]^{+}$} & 399.091 & 15.0 & [hexose + hexose]1 \\
\hline a22 & 431.222 & {$[\mathrm{C} 23 \mathrm{H} 30 \mathrm{~N} 2 \mathrm{O} 6+\mathrm{H}]^{+}$} & 431.218 & 9.3 & \\
\hline \multicolumn{6}{|c|}{ B: Negative ion mode } \\
\hline$\#$ & Obs. Mass $(m / z)$ & Chemical Formula & Theor. Mass $(\mathrm{m} / \mathrm{z})$ & $\Delta \mathrm{m}(\mathbf{p p m})$ & Tentative Assignment* \\
\hline b1 & 103.004 & {$\left[\mathrm{C} 3 \mathrm{H} 4 \mathrm{O} 4-\mathrm{H}^{-}\right.$} & 103.004 & 0.1 & malonic acid \\
\hline b2 & 105.019 & {$[\mathrm{C} 3 \mathrm{H} 6 \mathrm{O} 4-\mathrm{H}]^{-}$} & 105.019 & 2.2 & glyceric acid \\
\hline b3 & 127.016 & {$\left[\mathrm{C} 4 \mathrm{H} 4 \mathrm{~N} 2 \mathrm{O} 3-\mathrm{H}^{-}\right.$} & 127.014 & 15.7 & \\
\hline b4 & 133.014 & {$[\mathrm{C} 4 \mathrm{H} 6 \mathrm{O} 5-\mathrm{H}]^{-}$} & 133.014 & 1.3 & malic acid \\
\hline b5 & 135.029 & {$[\mathrm{C} 4 \mathrm{H} 8 \mathrm{O} 5-\mathrm{H}]^{-}$} & 135.029 & 1.9 & threonate \\
\hline b6 & 146.046 & {$[\mathrm{C} 5 \mathrm{H} 9 \mathrm{NO} 4-\mathrm{H}]^{-}$} & 146.045 & 3.0 & \\
\hline b7 & 173.008 & {$[\mathrm{C} 6 \mathrm{H} 6 \mathrm{O} 6-\mathrm{H}]^{-}$} & 173.009 & 3.6 & dehydroascorbic acid \\
\hline b8 & 174.019 & {$[\mathrm{C} 6 \mathrm{H} 7 \mathrm{O} 6-\mathrm{H}]^{-}$} & 174.017 & 11.5 & mono-dehydroascorbic acid \\
\hline b9 & 179.055 & {$[\mathrm{C} 6 \mathrm{H} 12 \mathrm{O} 6-\mathrm{H}]^{-}$} & 179.055 & 1.6 & hexose \\
\hline b10 & 191.053 & {$[\mathrm{C} 7 \mathrm{H} 12 \mathrm{O} 6-\mathrm{H}]^{-}$} & 191.056 & 16.6 & quinic acid \\
\hline b11 & 197.062 & {$[\mathrm{C} 13 \mathrm{H} 10 \mathrm{O} 2-\mathrm{H}]^{-}$} & 197.060 & 10.3 & \\
\hline b12 & 215.031 & {$\left[\mathrm{C} 6 \mathrm{H} 12 \mathrm{O} 6+\mathrm{Cl}^{-}\right.$} & 215.032 & 4.8 & hexose \\
\hline b13 & 225.057 & {$[\mathrm{C} 10 \mathrm{H} 1006-\mathrm{H}]^{-}$} & 225.061 & 17.8 & chorismic acid \\
\hline b14 & 226.995 & {$\left[\mathrm{C} 6 \mathrm{H} 8 \mathrm{O} 7+\mathrm{Cl}^{-}\right.$} & 226.996 & 1.8 & citric acid \\
\hline b15 & 239.073 & {$[\mathrm{C} 15 \mathrm{H} 12 \mathrm{O} 3-\mathrm{H}]^{-}$} & 239.071 & 8.4 & \\
\hline
\end{tabular}


Table 1: List of ion signals detected by direct IR-LDI-oTOF mass spectrometry in leaf samples of Nicotiana tabacum in (A) positive and (B) negative ion mode.* (Continued)

\begin{tabular}{|c|c|c|c|c|c|}
\hline b16 & 255.233 & {$[\mathrm{C} 16 \mathrm{H} 32 \mathrm{O} 2-\mathrm{H}]^{-}$} & 255.232 & 3.0 & palmitic acid \\
\hline b17 & 267.071 & {$[\mathrm{C} 9 \mathrm{H} 16 \mathrm{O} 9-\mathrm{H}]^{-}$} & 267.071 & 0.3 & \\
\hline b18 & 269.082 & {$[\mathrm{C} 16 \mathrm{H} 1404-\mathrm{H}]^{-}$} & 269.081 & 3.7 & \\
\hline b19 & 277.215 & {$[\mathrm{C} 18 \mathrm{H} 30 \mathrm{O} 2-\mathrm{H}]^{-}$} & 277.217 & 6.7 & $\gamma^{- \text {-linolenic acid }}$ \\
\hline b20 & 279.034 & {$[\mathrm{C} 13 \mathrm{H} 12 \mathrm{O} 5 \mathrm{~S}-\mathrm{H}]^{-}$} & 279.033 & 1.8 & \\
\hline b21 & 279.231 & {$[\mathrm{C} 18 \mathrm{H} 32 \mathrm{O} 2-\mathrm{H}]^{-}$} & 279.232 & 2.1 & a-linolenic acid \\
\hline b22 & 285.080 & {$[\mathrm{C} 16 \mathrm{H} 14 \mathrm{O} 5-\mathrm{H}]^{-}$} & 285.076 & 14.8 & \\
\hline b23 & 297.045 & {$[\mathrm{C} 16 \mathrm{H} 10 \mathrm{O} 6-\mathrm{H}]^{-}$} & 297.047 & 4.4 & \\
\hline b24 & 309.044 & {$[\mathrm{C} 17 \mathrm{H} 10 \mathrm{O} 6-\mathrm{H}]^{-}$} & 309.040 & 12.2 & \\
\hline b25 & 310.147 & {$[\mathrm{C} 19 \mathrm{H} 21 \mathrm{NO} 3-\mathrm{H}]^{-}$} & 310.144 & 8.4 & \\
\hline b26 & 313.075 & {$[\mathrm{C} 17 \mathrm{H} 14 \mathrm{O} 6-\mathrm{H}]^{-}$} & 313.075 & 1.3 & \\
\hline b27 & 315.090 & {$[\mathrm{C} 17 \mathrm{H} 16 \mathrm{O} 6-\mathrm{H}]^{-}$} & 315.090 & 0.9 & \\
\hline b28 & 325.044 & {$[\mathrm{C} 9 \mathrm{H} 15 \mathrm{~N} 2 \mathrm{O} 9 \mathrm{P}-\mathrm{H}]^{-}$} & 325.043 & 2.6 & \\
\hline b29 & 327.054 & {$[\mathrm{C} 17 \mathrm{H} 12 \mathrm{O} 7-\mathrm{H}]^{-}$} & 327.051 & 8.7 & \\
\hline b30 & 353.088 & {$[\mathrm{C} 16 \mathrm{H} 18 \mathrm{O} 9-\mathrm{H}]^{-}$} & 353.087 & 0.7 & chlorogenic acid \\
\hline b31 & 359.118 & {$[\mathrm{C} 12 \mathrm{H} 24 \mathrm{O} 12-\mathrm{H}]^{-}$} & 359.119 & 2.8 & [hexose + hexose] 1 \\
\hline b32 & 371.111 & {$[\mathrm{C} 2 \mathrm{OH} 20 \mathrm{O} 7-\mathrm{H}]^{-}$} & 371.113 & 5.8 & \\
\hline b33 & 377.083 & {$[\mathrm{C} 12 \mathrm{H} 22 \mathrm{O} 11+\mathrm{Cl}]^{-}$} & 377.084 & 3.9 & dihexose \\
\hline b34 & 395.095 & {$\left[\mathrm{C} 12 \mathrm{H} 24 \mathrm{O} 12+\mathrm{Cl}^{-}\right.$} & 395.095 & 0.8 & [hexose + hexose] 1 \\
\hline b35 & 447.132 & {$[\mathrm{C} 22 \mathrm{H} 24 \mathrm{O} 8-\mathrm{H}]^{-}$} & 447.129 & 8.4 & \\
\hline b36 & 457.278 & {$\left[\mathrm{C} 29 \mathrm{H} 42 \mathrm{O} 2+\mathrm{Cl}^{-}\right.$} & 457.286 & 17.3 & \\
\hline b37 & 477.145 & {$[\mathrm{C} 16 \mathrm{H} 30 \mathrm{O} 16-\mathrm{H}]^{-}$} & 477.145 & 0.5 & \\
\hline
\end{tabular}

${ }^{*}$ Assignment of chemical composition is based on precise mass measurements, comparison of isotopic patterns, and comparison with databases and literature addressing Nicotiana tabacum metabolites; only signals consistently exhibiting an $s / n$ of 10 or better are listed. ${ }^{1}$ Possible gas phase adducts.

tivars of Nicotiana tabacum, the resistant cultivar SNN and the nonresistant cultivar Xanthi, which exhibits no or only a weak HR. In $S N N$, high JA levels appear transiently during the first hour post infection [70]. The rapid decline in JA after its initial burst (which is most likely due to the inhibition of the LOX cascade of the JA biosynthesis pathway) is possibly reflected in the IR-LDI-oTOF mass spectra by the "cross-over" between $\gamma$-LA (for which signals increase) and its peroxidation products (for which signals decrease). In contrast to JA, the levels of the phenolic hormone SA, known to inhibit JA biosynthesis $[8,52]$, increase monotonously with time after injection of zoospores. The increase in SA concentration in the tobacco - Phytophthora system after $1 \mathrm{hpi}$ is further supported by the appearance of PR1, a marker for the SA pathway [17]. In the LDI MS profile, infection-induced biosynthesis of SA may be reflected by the appearance of its phenolic precursors chorismic acid and chlorogenic acid (data not shown) [1,12]. In Xanthi, the initial JA burst was small and the increase in SA levels was retarded, compared to those seen in $S N N$, reflecting the difference in their response against the pathogen.

\section{Principal component analysis}

A PCA transformation can help to visualize the most significant differences in the mass profiles between samples and allows similar samples to be grouped together. The first principal component (PC1) is most strongly influenced by the combination of ion signals that exhibit the largest change between the recorded spectra. In a similar way, subsequent principal components (PC2, $\mathrm{PC} 3$, etc) represent less influential changes that can, however, still help to identify particular features of the investigated system. Figure 4 shows the PC1 vs. PC2 score plot of the unsupervised PCA performed with the positive mode ion spectra (see Material and Methods for details). This graphic representation reveals a high correlation between the MS profiles of the six different groups of investigated samples. Based on PC2 values, they are essentially grouped into one of three "qualitative" clusters. Qualitatively, these clusters may be seen as representing: (I) untreated samples (blank near a placebo zone, $\mathrm{B}_{\mathrm{P}}$ ); (II) "stressed" samples from local water infiltration (placebo near blank or infection zone; $\mathrm{P}_{\mathrm{B}}, \mathrm{P}_{\mathrm{I}}$ ); and (III) "stressed" samples from infection $\left(I_{P}, I_{B}, B_{I}\right)$. This qualitative analy- 
sis suggests that PC2 may capture both systemic and local stress signals, though the local stress response is presumably reflected stronger. In the score plot, samples are not differentiated with respect to the time post treatment. As can be seen in Figure 5, mass spectra of the infected samples tend to show an increase of the PC1/PC2 values derived from their metabolic profile with time post infection, while the picture for the other sample treatments is less clear.

\section{Identification of key metabolites and their pathways}

The corresponding loading plots (displayed in Additional file 2) identify which metabolites, and therefore their associated pathways, contribute the most to the variance of the two principal components. Some of these metabolites can directly be related to known metabolic processes. Examples for PC1: phaseic acid $(\mathrm{m} / z$ 281.140, cf. to Table 1 for the type of ion formation) relates to ABA turnover (see hormone analysis above); tyramine $(\mathrm{m} / \mathrm{z}$ 138.091, $c f$. to Table 1) relates to the phenolic metabolism and SA turnover (see hormone analysis above). Examples for PC2: HOO- $\gamma$-LA $(m / z 311.220, c f$. to Table 1$)$ and its methyl ester $(m / z 325.236$, $c f$. to Table 1$)$ relate to LOX activity and JA turnover (see hormone analysis above). The loading plots also revealed MS signals that exhibit a high correlation in the PCA, for which the identity of the corresponding ions, however, is currently unknown. For example, the ion signal with an $\mathrm{m} / z$ value of 318.153 (Table 1) shows a strong correlation with PC1. Based on its mass, this metabolite could possibly be either a glycosylated ester of the alkaloid retronecin [71], or a gas phase adduct of protonated tyramine + hexose (or both). A second signal with an $m / z$ value of 361.211 (Table 1 ) shows a strong correlation with PC2. This species might be peroxidated-chlorinated- $\alpha$-methyl-linolenate or a gas phase adduct of protonated peroxidated-methyl- $\gamma$-linolenate with hydrochloric acid. Further studies are needed to elucidate the chemical identity of these species. These examples demonstrate that the defence response of tobacco (SNN) toward Phytophthora Nicotianae can only be more fully captured by the combination of the two main principal components (PC1 \& PC2).

\section{Biological response index}

Because only locally infected tissue of the SNN cultivar undergoes HR, while neighboring leaf areas do not exhibit HR, two qualitatively lines can be drawn in the PC1 vs. PC2 score plot of Figure 4. The first one, labeled as "Thr" (threshold), is a line that separates all measured samples from tobacco (SNN) into two regions: (a) $+\mathrm{HR}$ (undergoing HR) and (b) -HR (not undergoing HR), respectively. The second one is perpendicular to "Thr", and is labeled as $\mathrm{f}(\mathrm{PC} 1, \mathrm{PC} 2)$. The projection of the $\mathrm{PC} 1$ vs. PC2 data points onto this line - $\mathrm{f}(\mathrm{PC} 1, \mathrm{PC} 2)$ - can be regarded as reflecting the "stress status" of the samples. One may thus call this one-dimensional projection an integrated "Biological Response Index" (BRI).

Figure 5A shows the so-derived BRI values for the differently treated SNN and Xanthi samples for time points between 1 to $9 \mathrm{hpi}$. For convenience, the mean of the BRI values derived for "untreated" samples $\left(B_{P}\right)$, where a minimum of metabolic effects can be expected to occur, was furthermore arbitrarily set to zero. The highest BRI values of $\sim 7$ were derived for infected $S N N$ samples at 6 and 9 hpi, while infected Xanthi samples exhibit intermediate values of $\sim 4$, which are essentially constant at all time points, and also similar to the BRI values obtained for $P_{I}$ and $\mathrm{B}_{\mathrm{I}}$ SNN samples.

To further evaluate the possible relevance of the BRI, we examined how well the BRI values correlate with the number of cells that had undergone HR by performing classical dead cell count analysis of identically treated samples. The correlation between the two values is plotted in Figure 5B. Cell death is a consequence of (SA mediated) $\mathrm{HR}$ and proportional to the strength of the plant defence response. The BRI vs. DCC plot (Figure 5B) reveals a non-linear function of the form $\mathrm{Aa}+$ $b^{*} \operatorname{Ln}(\mathrm{DCC})$ " between the qualitative BRI and the quantitative DCC values. The non-linearity of the relationship may be interpreted as describing the complex metabolic (and hormonal) transition, starting from initial local or "micro-systemic" stress or infection responses to a specific defence reaction. BRI values around 5 reflect the transition from more or less reversible stress response to irreversible processes (such as HR) which inevitably result in cell death (represented by the line labeled "Thr" in Figure 4), but this transition is not abrupt.

The BRI parameter appears to only reflect the strength of the local defence response toward the infection. Treatments applied on the opposite side of the midvein did not notably influence the BRI value obtained for the infected samples. This demonstrates that at least within the time frame of 1 - $9 \mathrm{hpi}$, the analysis of leaf sections which develop a HR will not be dramatically affected by major systemic effects which traversed the major veins (Additional file 3). However, the occurrence of more minor systemic effects, that are influencing the overall metabolic profile, is well reflected by the original PCA score plot. For example, in the PC1 vs. PC2 score plot of Figure 4, the metabolic profile of blank control samples is placed adjacent to an infection site, suggesting that PC2 may capture "micro-systemic" metabolic responses

Employing loading plots (Additional file 2) to find those metabolites that are associated with a high BRI value, two ion species with $m / z$ values of 269.170 and 431.222 , respectively, were identified to exhibit a particular high correlation with the BRI. The metabolic time profiles of 


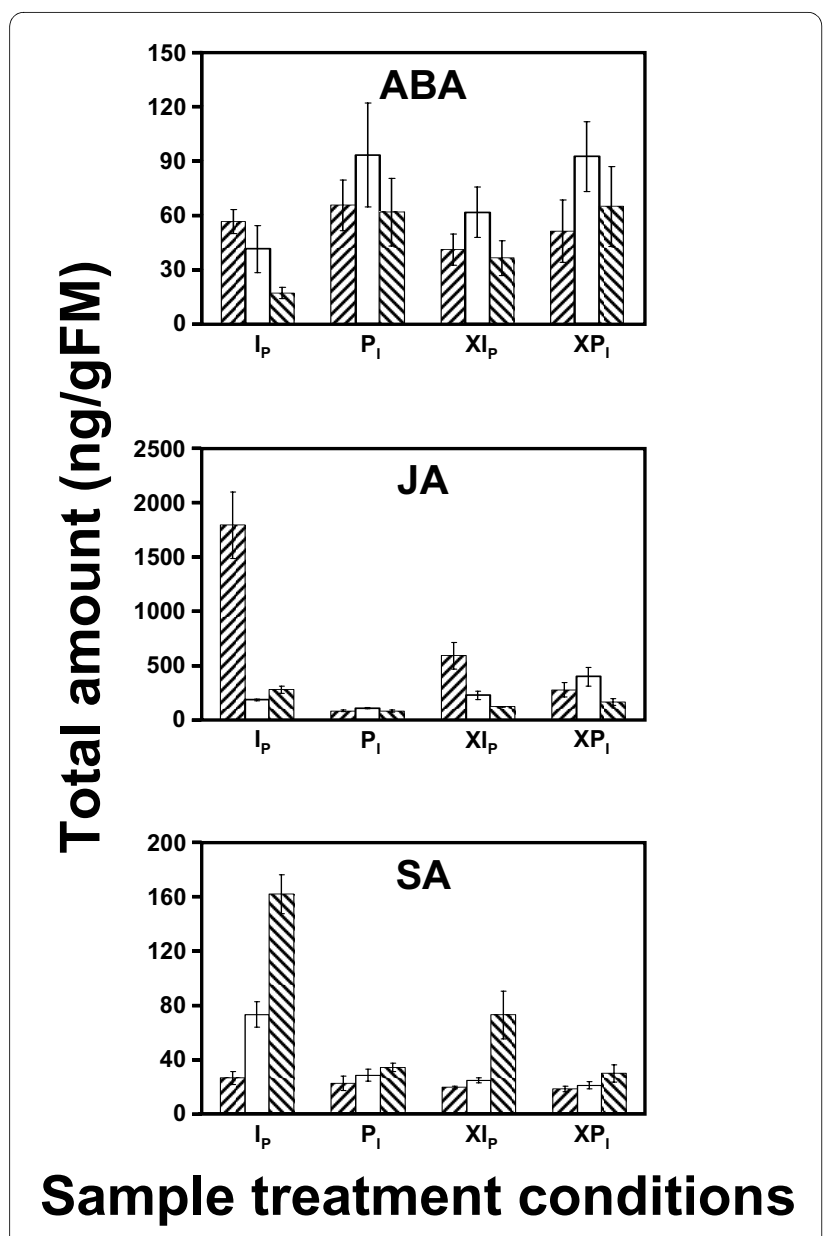

$\mathbb{Z} 1 \mathrm{hpi} \quad \square 3 \mathrm{hpi} \mathbb{N} 6 \mathrm{hpi}$

Figure 3 Quantitative LC-ESI MS/MS analysis of phytohormones (time-profiles). Absolute amount of the major signaling phytohormones ( $A B A, J A$, and $S A$ ) per weight of fresh leave material in two different cultivars of Tobacco (SNN, and Xanthi), determined by LC-ESI MS/MS in multiple reaction mode (MRM). Samples labeled with a preceding "X*" represent samples from N. tabacum (cv. Xanthi), * represents the sample treatment (for detailed explanation of the nomenclature employed, see text).

these, as yet unidentified compounds, are displayed in Figure 6 . Both species essentially show the same expression profile with time post treatment. The mass difference of $162.052 \mathrm{u}$ suggests that these two metabolites likely represent the deglycosylated/glycosylated derivative of each other, where the sugar moiety would be a hexose. The strong correlation with the BRI value and thus to the infection-related stress response renders them as putative biomarkers for monitoring the HR defence response. Future studies will aim to structurally characterize the two compounds.

\section{Conclusions}

IR-LDI-oTOF mass spectrometry allowed the rapid and simultaneous detection of a wide range of naturally occurring (unlabeled) metabolites directly from leaf lamina samples of tobacco plants. Changes in time for the signals of secondary metabolites (such as phenolics, alkaloids, and oxylipins) and primary metabolites (such as hexoses and dihexoses) were recorded for differently treated samples. The recorded changes in the metabolome indicated that the JA/SA-defence cascades as well as the ABA turnover cascade were involved in stress/infection response. The involvement of these three cascades can explain the majority of the physiological changes that were previously observed during this plant - pathogen infection $[17,20]$. The hypothesis that the JA/SA-defence cascades as well as ABA turnover are important for the development of HR was successfully verified by LC-ESIMS/MS analysis of phytohormones.

From the PCA of the positive ion mode spectra a qualitative stress response factor (denominated: biological response index, BRI) was derived. By employing the PCA loading plots, several ion signals were identified to be strongly correlated with the local defence response against the pathogen. While many of these metabolites have been described previously to be involved in stress/ infection response, two ion signals that are showing a particular strong correlation with the BRI could so far not be assigned. Potentially, the two compounds can serve as biomarkers for monitoring the HR. Thus, IR-LDI-oTOF MS analysis in combination with PCA may help to not only to rapidly record complex metabolic transitions during specific stress responses, but also to identify such potential biomarkers.

Furthermore, two additional advantages of the LDIoTOF MS method are that it first allows to record metabolic profiles directly from fresh tissue and second provides a high lateral resolution. This simplifies and accelerates the analysis, on the one hand, and facilitates the mapping of the spatial spread of the metabolic response across the leaf on the other. Recent developments even indicate the possibility to analyze individual plant cells [39]. Thus, in nearby future; this method could be beneficial for studying developmental processes, which exhibit distinctive spatial orientation as well as several types of stress responses. In the case of the defence of the N. tabacum cultivar SNN toward P. nicotianae, the HR is strictly a localized process, however the defence response may not need to be (there might be signals going out which prepare neighboring cells to execute $\mathrm{HR}$ faster). Hence, future high resolution metabolome mapping could be an extremely powerful tool, e.g. for detecting the spread of an infection and for analyzing the interaction between infected and non-infected cells.

\section{Materials and methods Chemicals}

Deuterated abscisic acid $\left(\mathrm{D}_{2}-\mathrm{ABA}\right)$ and jasmonic acid $\left(D_{2}\right.$-dihydro-JA) were purchased from OlChemIm Ltd 


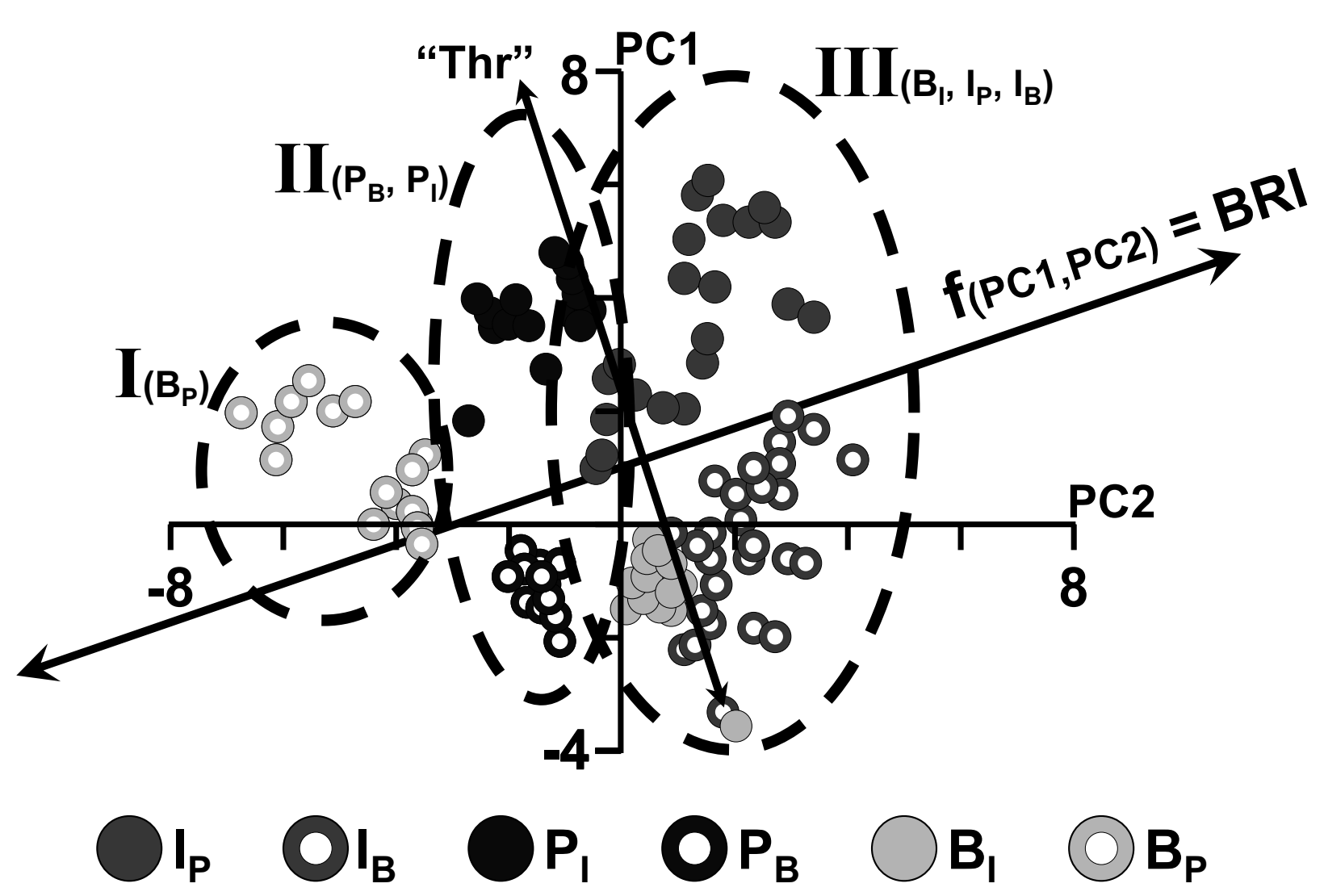

Figure 4 Principal component analysis of the IR-LDI-oTOF MS spectra. PC1 vs. PC2 score plot of an unsupervised PCA of the positive ion mode IR-LDI mass spectra acquired from differently treated samples of Nicotiana tabacum (cV. SNN). Based on their distribution with respect to the PC2-axis, the samples can, qualitatively, be grouped into three clusters: (I) untreated samples (blank near a placebo zone, $B_{p}$ ); (II) "stressed" samples from local water infiltration (placebo near blank or infection zone; $\left.P_{B}, P_{1}\right)$; and (III) "stressed" samples from infection $\left(I_{p}, I_{B}, B_{\mid}\right)$. The line labeled as "Thr" separates samples that do not undergo HR (-HR) from those that undergo HR (+HR) (i.e. top right = high cell death, bottom left = low cell death). The line $\mathrm{f}(\mathrm{PC1}, \mathrm{PC2})$ is displayed as the perpendicular line to "Thr". The "stress status" (BRI value, displayed in Figure 5) for each sample is obtained from the projection of any point to $\mathrm{f}(\mathrm{PC} 1, \mathrm{PC} 2)$.

(Olomouc, Czech Republic); deuterated salicylic acid $\left(\mathrm{D}_{4^{-}}\right.$ $\mathrm{SA}$ ), and all other chemicals/solvents were purchased from Sigma-Aldrich (Steinheim, Germany) and were used without further purification.

\section{Plant and pathogen material}

Plants were grown in a climate chamber with $24^{\circ} \mathrm{C}$ and $22^{\circ} \mathrm{C}$ (day and night temperature, respectively), with a 14 hour photoperiod (light levels of $300 \mu \mathrm{mol}$ quanta $\cdot \mathrm{m}^{-2} \cdot \mathrm{s}^{-}$ 1). Source leaves of six to eight weeks old plants from two cultivars of Nicotiana tabacum were used. Because only about two source leaves of this age are found in an individual tobacco plant, several identically treated plants were employed for this study. The cultivar SNN is resistant against the employed pathogen and capable of developing a strong HR; the other cultivar, Xanthi, is susceptible and does not produce sizable HR (thus, it was employed as a biological reference) [17]. Cultivation of Phytophthora nicotianae van Breda de Haan isolate 1828
(DSMZ, Braunschweig, Germany), the production of zoospores, and the infection procedure were performed as described previously $[17,20]$.

\section{Preparation of samples for IR-LDI-oTOF MS}

Three types of samples were collected from plant leaves: Blank samples (B) were from untreated leave areas, placebo samples $(\mathrm{P})$ from areas which got sterile tap water injected to represent the pure injection stress, and infected samples (I) which where injected a suspension of $750 \pm 250$ zoospores per $\mu \mathrm{l}$. In case of the P and I samples, several injections of either tap water or zoospore suspension were placed close to each other within an area of $\sim 20$ $\mathrm{cm}^{2}$; the total injected volume per sample was $1 \mathrm{ml}$. The liquid was slowly infiltrated with a fine syringe to fill the air space in the spongy mesophyll of the leaves. The benefit of employing Phytophthora nicotianae (which initiates local HR responses in leaves of resistant tobacco) as a pathogen and using an artificial infection procedure 


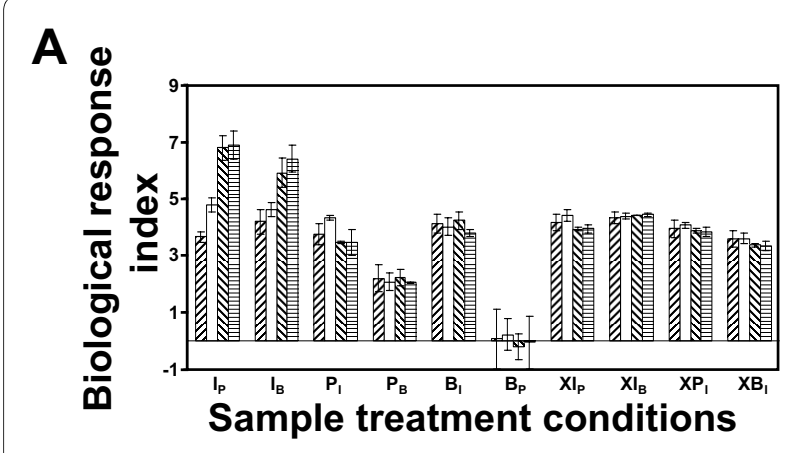

B

U/ 1 hpi $\square 3$ hpi 6 hpi

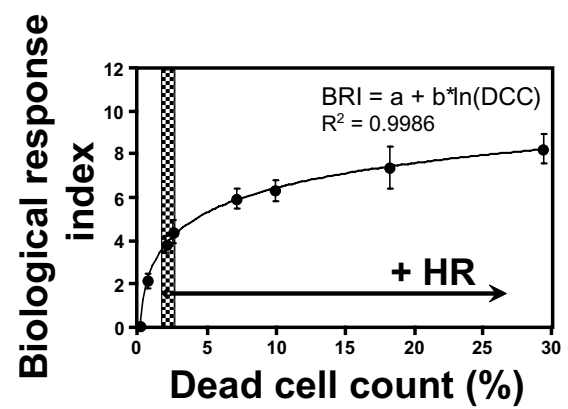

Figure 5 Biological response index and comparison with dead cell count values. (A) Biological response index (BRI, $\mathrm{f}(\mathrm{PC} 1, \mathrm{PC} 2)$ ) obtained from the PCA shown in Figure 4 (see text for detailed explanation of the procedure). Samples labeled with a preceding " $X^{*}$ " represent samples from $N$. tabacum (cv. Xanthi), ${ }^{*}$ represents the sample treatment (see text for details). (B) Comparison between BRI and the dead cell count (DCC, \%) determined for differently treated SNN samples. Solid line: Best fit according to $B R I=a+b^{*} \operatorname{Ln}(D C C)$, where $a$ $=2.6044$ and $b=1.6535\left(R^{2}=0.9986\right)$. The shaded area indicates the threshold in terms of DCC that defines a positive HR.

(local infiltration of leaves) is that the infection area is well defined and the mesophyll cells respond nearly synchronously. To determine whether, besides the local reactions of interest, there are also systemic effects, combinations of the three treatments were applied to three sets of leaves. One specific treatment was applied on one side of the midvein and the second was applied to the other. Subscripts identify this treatment; for example, $\mathrm{I}_{\mathrm{p}}$ would be a sample taken from a zoospore-injected site with a placebo (i.e. water injection) on the opposite side of the midvein.

For each treatment, injections were placed on a given side of the leaf in areas, where the different time points were separated by side veins (i.e. one distal zone for each time point) in order to minimize crosstalk between different samples [72]. Typically, three discs of $7.5-15 \mathrm{~mm}$ in diameter were cut out of each treatment area and analyzed by IR LDI-oTOF MS. The punch sites were all placed as close as possible to the point of injection. A sketch illustrating the example of a leave with spore injec- tion on the right side of the leaf and a blank of the left is shown in Figure 1.

Samples were shock-frozen in liquid nitrogen immediately after dissection, and subsequently stored at $-80^{\circ} \mathrm{C}$ until the MS measurements. Immediately prior to the IRLDI MS measurement, and while the leaf was still frozen, the lower cuticle of the leaves was removed using adhesive tape. Leaf samples were placed on a standard microscope glass slide "upside down" (i.e. the lower epidermis side of the leaf was "face-up") using adhesive (G304, Plano W. Plannet GmbH, Wetzlar, Germany) (Figure 1). The glass slide was mounted into a custom-made MALDI sample plate using double-sided tape.

To visualize the changes in the metabolic profile that are specifically induced by infection from those initiated by mechanical or osmotic stress (due to leaf infiltration or wounding by sample collection) IR-LDI mass spectra acquired from pathogen-infiltrated (infected) leaf sections were compared with those recorded from waterinfiltrated (placebo), and untreated (blank) leaf sections. Furthermore, to minimize the local variations in the amount of zoospores present in the tissue, mass profiles were taken from the middle of the injection zones. A sketch illustrating this procedure is provided in Additional file 4.

Samples were collected at time points of $1,3,6$, and 9 hpi. Typically, the injected water exuded/evaporated within $45 \mathrm{~min}$. Because a low mass spectral quality was obtained from plant tissue containing excessive water in the air space of the spongy mesophyll, 1 hpi was chosen as the earliest measurement time point. By comparing

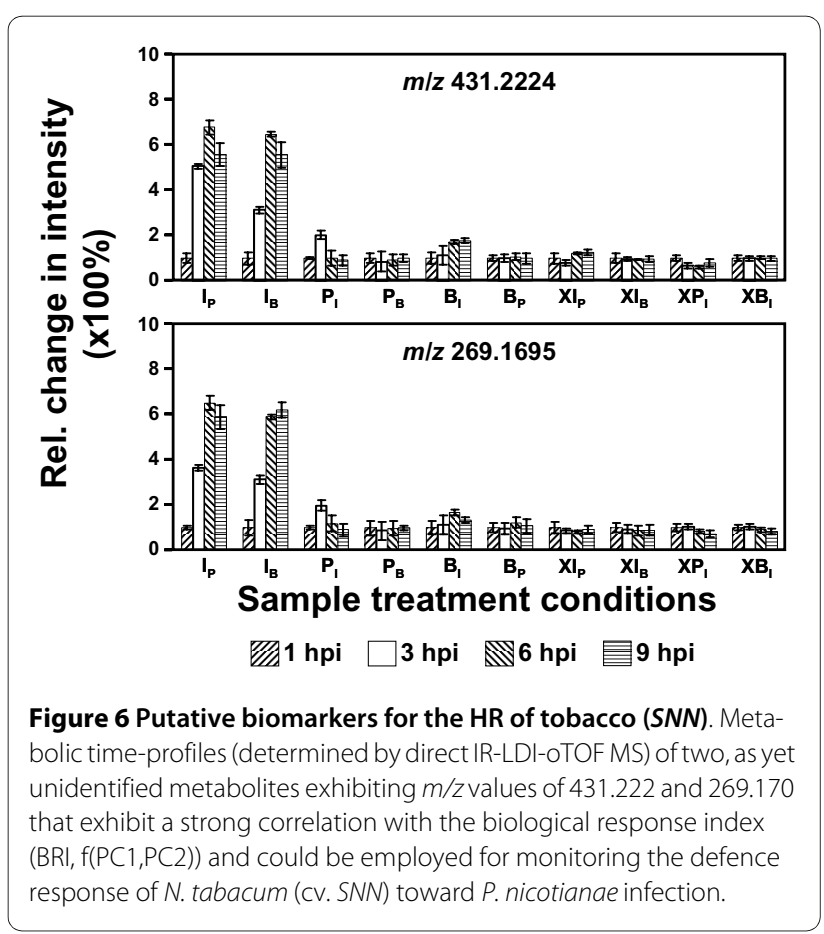


changes of the relative intensity of an ion signal determined at the different time points, normalized to its intensity at the reference point of $1 \mathrm{hpi}$, "key metabolites" that exhibit significant changes with time post treatment can be identified. Care was taken that samples did not reside inside the fine vacuum of the MS ion source longer than $10 \mathrm{~min}$ to avoid excessive water loss by dehydration.

\section{IR-LDI-OTOF MS analysis of metabolites}

The mass spectrometer has been described in detail before [34,40]. This instrument is equipped with an UVlaser $\left(\mathrm{N}_{2}\right.$ laser, $\left.\lambda=337 \mathrm{~nm}\right)$ and an Er:YAG laser (Speser, Spektrum, Berlin, Germany). The latter is an IR-laser that emits pulses of $\sim 150 \mathrm{~ns}$ duration at a wavelength of 2.94 $\mu \mathrm{m}$ and at a repetition rate of $2 \mathrm{~Hz}$. The IR-laser beam irradiated the leaf surfaces at an angle of incidence of $45^{\circ}$. The focal spot size was slightly elliptical and had an area of $\sim 150 \times 200 \mu \mathrm{m}^{2}\left(1 / \mathrm{e}^{2}\right.$ intensity definition), the beam profile was near-Gaussian. $\mathrm{N}_{2}$ was used as buffer gas for collisional cooling and focusing [44]. The pressure in the sample region of the ion source was adjusted to $\sim 0.7$ mbar [46]. For ion generation, a laser fluence (energy per pulse and area) of $\sim 25 \mathrm{~kJ} \cdot \mathrm{m}^{-2}$ was typically applied. At this fluence, tissue layers of about $50 \mu \mathrm{m}$ in depth are removed per laser pulse in the central part of the focused beam, allowing the analysis of the content of lysed cells. 120 laser shots where accumulated for each single spectrum. These successive exposures were applied over an area of typically $2 \mathrm{~mm}^{2}$ by manually moving the sample target under the fixed laser beam in a zigzag pattern. This way, any given sample location was exposed to no more than four laser pulses, thereby avoiding a full penetration of the sample. Two mass spectra were recorded from each individual sample disk.

Measurements were performed in positive and negative ion mode using time-of-flight voltages of $\pm 10 \mathrm{kV}$. The mass resolution (FWHM) was about 6,000 in both ion modes. Using the monoisotopic ion signals of Angiotensin $\mathrm{I}([\mathrm{M}+\mathrm{H}]+m / z$ 1296.6853) and 2,5-dihydroxybenzoic acid (DHB) UV-MALDI matrix molecules $\left([\mathrm{M}+\mathrm{H}]^{+}\right.$ $m / z 155.0344)$ for external calibration, a mass accuracy of about $\sim 20 \mathrm{ppm}$ was achieved for the $\mathrm{m} / z$ range between 100 - 500. All ions were detected as singly charged species. With internal calibration, using signals of metabolites of known identity (e.g. nicotine, hexose, and dihexose), the mass accuracy could be improved to $\sim 6$ $\mathrm{ppm}$. Mass spectra were partially processed using MoverZ software (freeware edition, Genomics Solution, Ann Arbor, MI, USA).

Although HR signals are locally triggered in the pathogen infection area $[17,21]$, plants possess the ability to generate disease resistance against further infections in healthy (uncompromised) parts by employing secondary metabolites as infection messengers. As shown in Addi- tional file $4 \mathrm{~A}$, the location from where the sample disk was taken within the same distal zone may to some extent influence the metabolic pattern in the mass spectra, due to changes in the local concentrations of zoospores in the tissue. To account for this source of variability, all sample disks were taken from the center of the placebo or infected areas located inside one distal zone and as equidistance as possible to the multiple points of injection. In the case of the blank samples, the sample disks were taken from the center of their respective distal zones (Additional file 4B).

If the samples were taken from the center of their respective distal zones, the main parameters that influenced the relative signal intensities and ion patterns were the amount of water contained in the leaves and the applied laser fluence (see above, preparation of samples for IR-LDI-oTOF MS). Attempts to improve a quantitative data evaluation by finding an endogenous "internal standard" were not successful. Therefore, care was taken to follow a consistent preparation and measurement protocol. Under these conditions, the variation in the intensities of specific metabolite signals obtained from identically prepared and treated samples (from the same or different plants) was between $5-30 \%$. This is illustrated by the error bars in the graphs.

\section{Identification of metabolites}

Table 1 lists the presumable chemical composition and type of ion formation for all $\sim 60$ consistently detected ion species, in positive (Table A1A) and negative (Table B1B) ion mode, along with the experimental and calculated $\mathrm{m} /$ $z$ values. Positively charged ions are mostly detected as protonated $[\mathrm{M}+\mathrm{H}]+$ and partially as sodiated/potassiated $[\mathrm{M}+\mathrm{Na}]^{+} /[\mathrm{M}+\mathrm{K}]^{+}$species, negatively charged ions as deprotonated $[\mathrm{M}-\mathrm{H}]^{-}$and partially as chlorinated molecules $[\mathrm{M}+\mathrm{Cl}]-$ (identified by the distinct ${ }^{35} \mathrm{Cl} /{ }^{37} \mathrm{Cl}$ isotopic distribution of chlorine).

In addition, a few gas phase adducts such as [hexose + hexose $+\mathrm{K}]^{+}$and [tyramine + hexose $\left.+\mathrm{H}\right]^{+}$are presumably also detected due to the soft desorption/ionization conditions [40]. Since the oTOF instrument does not provide a tandem MS option for structural characterization of ions, isobaric species can not be differentiated. Hence, putative identification of metabolites is based on the comparison of experimental and theoretical mass values (which had to coincide within $20 \mathrm{ppm}$ ), the comparison of experimental and theoretical isotopic patterns, and the use of various databases addressing general plant metabolites, as well as literature addressing Nicotiana tabacum metabolism. The following databases were used in this study: ChemBioFinder http://chembiofinder.cambridgesoft.com/; Chemspider http://www.chemspider.com/; Kegg http://www.genome.jp/kegg/; LipidBank http://lipidbank.jp/; LipidMaps http://www.lipidmaps.org/; Met- 
lin http://metlin.scripps.edu/Plant metabolomic pathway http://plantcyc.org/; and Welmetser http:// maths.sci.shu.ac.uk/students/bioinformatics/ Bindal_Nidhi/WELMETSER.pl.

\section{Principal component analysis}

The oTOF mass spectra were converted to ASCII files using the custom-made data acquisition software of the mass spectrometer (TOFMA v99.6; developed by W. Ens and colleagues at the University of Manitoba, Winnipeg, CA). The ASCII files were converted into Microsoft excel sheets using a home-made program to become compatible with the PCA program RapidMiner 4.600 (Rapid-I, Dortmund, Germany). Only ion signals that were consistently detected with a signal-to-noise $(s / n)$ ratio of at least 10 at any of the monitored time points for SNN plants were used for the unsupervised PCA. Because the focus of this study was on the resistant $S N N$ cultivar, those ions which were unique to Xanthi and not seen in $S N N$ with the necessary $s / n$ ratio were excluded from the PCA.

\section{Preparation of samples for LC-ESI MS}

LC-ESI MS quantitation of selected metabolites (phytohormones) was performed based on the work published by the Baldwin group (Max Planck Institute for Chemical Ecology in Jena, Germany) [28-30]. The infection procedure was identical to the one employed for the IR-LDIoTOF MS measurements. Eight disks of $0.9 \mathrm{~mm}$ in diameter were cut out with a puncher. Samples were shockfrozen in liquid nitrogen immediately after dissection and subsequently stored at $-80^{\circ} \mathrm{C}$ in $2 \mathrm{ml}$ vials. Free phytohormones were extracted by homogenizing $\sim 100 \mathrm{mg}$ of leaf material in a SamplePrep 2000 Geno/Grinder (SPEX CertiPrep, Metuchen, NJ, USA), employing FastPrep tubes containing $900 \mathrm{mg}$ of lysing matrix (BIO 101; Vista, California, USA) and $1 \mathrm{ml}$ of ethyl acetate spiked with $100 \mathrm{ng}$ of deuterated internal standards $\mathrm{D}_{4}-\mathrm{SA}$ and $\mathrm{D}_{2}-\mathrm{ABA}$; and $40 \mathrm{ng}$ of $\mathrm{D}_{2}$-dihydro-JA. Phytohormones were extracted by reciprocal shaking at $6.5 \mathrm{~m} \mathrm{~s}^{-1}$ for $2 \mathrm{~min}$; consecutively, they were centrifuged at $13,000 \mathrm{rpm}$ for $20 \mathrm{~min}$ at $4^{\circ} \mathrm{C}$. The supernatants were evaporated to dryness in a vacuum concentrator at $30^{\circ} \mathrm{C}$. The dry residue was re-dissolved in $600 \mu \mathrm{l}$ of methanol $(70 \%)$ and centrifuged at $13,000 \mathrm{rpm}$ for $10 \mathrm{~min}$ at $4^{\circ} \mathrm{C}$. An aliquot $(500 \mu \mathrm{l})$ was transferred to HPLC vials for measurement.

\section{LC-ESI MS/MS analysis of phytohormones}

The transferred aliquots were quantified using an LC-ESI tandem mass spectrometry system (Varian 1200, Palo Alto, USA). $10 \mu \mathrm{l}$ of each extracted sample were injected onto a ProntoSIL column (C18; $5 \mu \mathrm{m}, 50 \times 2 \mathrm{~mm}$; Bischoff, Leonberg, Germany) attached to a precolumn (C18, $4 \times 2$ mm; Phenomenex, Aschaffenburg, Germany). The mobile phase comprised solvent A $(0.05 \%$ formic acid) and solvent $B$ (methanol) used in a gradient mode (time/concentration $\left[\mathrm{min} / \%\right.$ ] for B: $0.0 / 15 ; 1.5^{\prime} / 15 ; 4.5^{\prime} /$ $\left.98 ; 12.5^{\prime} / 98 ; 13.0^{\prime} / 15 ; 15.0^{\prime} / 15\right)$ with a flow of (time/flow $[\mathrm{ml} / \mathrm{min}]: 0.0^{\prime} / 0.4 ; 1.0^{\prime} / 0.4 ; 1.5^{\prime} / 0.2 ; 10.0^{\prime} / 0.2 ; 10.5^{\prime} / 0.4$; $\left.15.0^{\prime} / 0.4\right)$. Compounds were detected as negative ions in multiple reaction monitoring (MRM) mode. Molecular ions $[\mathrm{M}-\mathrm{H}]-$ at $m / z 137,209,263(\mathrm{SA}, \mathrm{JA}$, and ABA, respectively) and 141, 211; 265 (deuterated derivatives of the compounds, respectively) were fragmented using 15 $\mathrm{eV}$ collision energy. The ratios of ion intensities of nondeuterated and deuterated product ions were used to quantify endogenous SA, JA, and ABA.

\section{Dead cell count analysis}

The infection procedure was identical to the one employed for the IR-LDI-oTOF MS measurements. Dead cell count was performed with $0.5 \mathrm{mg} \mathrm{ml}^{-1}$ propidium iodide aqueous solution based on the work published by the Weis group (Institute of Botany, Westfälische Wilhelms-Universität Münster, Germany) [21]. Cells with disrupted membranes (dead cells) allow the fluorescence dye propidium iodide to enter into the cytoplasmatic region, thus indicating cell death. The fluorescence was detected at $590-650 \mathrm{~nm}$ after excitation at $488 \mathrm{~nm}$ using a confocal laser scanning microscope (TCS SPE2 with inverse DM IRB-microscope, Leica, Wetzlar, Germany) [21].

\section{List of abbreviations}

2,5-DHB: (2,5-Dihydroxybenzoic acid); ABA: (Abscisic acid); ASCII: (American standard code for information interchange); $\mathrm{B}_{\mathrm{I}}$ : (Sample taken from an untreated site with an infected, i.e. spore-injected, on the opposite side of the midvein); $\mathrm{B}_{\mathrm{p}}$ (Sample taken from an untreated site with a placebo, i.e. water injection, on the opposite side of the midvein); BRI: (Biological response index); $\mathrm{D}_{2}-\mathrm{ABA}$ : (Deuterated abscisic acid); $\mathrm{D}_{2}$-dihydro-JA: (Deuterated dihydro-jasmonic acid); $\mathrm{D}_{4}$-SA: (Deuterated salicylic acid); DCC: (Dead cell count); DSMZ: (German collection of microorganisms and cell culture - Deutsche Sammlung von Mikroorganismen und Zellkulturen GmbH); Er:YAG: (Erbium-doped yttrium aluminum garnet); ESI: (Electrospray ionization); ET: (Ethylene); FA: (Free fatty acid); FM: (Fresh mass - weight of fresh leaf); GC: (Gas chromatography); $\gamma$-LA: ( $\gamma$-linolenic acid); HOO- $\gamma$-LA: (Peroxidated $\gamma$-linolenic acid); hpi: (Hours post infiltration - hours post infection); HR: (Hypersensitive response); $\mathrm{I}_{\mathrm{B}}$ : (Sample taken from a spore-injected site with a blank, i.e. untreated, on the opposite side of the midvein); $\mathrm{I}_{\mathrm{p}}$ : (Sample taken from a spore-injected site with a placebo, i.e. water injection, on the opposite side of the midvein); IR: (Infrared); JA: (Jasmonic acid); LA: (linolenic acid); LC: (Liquid chromatography); LDI: 
(Laser desorption/ionization); LOX: (Lipoxygenase); MALDI: (Matrix assisted laser desorption/ionization); MRM: (Multiple reaction monitoring); MS: (Mass spectrometry); MS/MS: (Tandem mass spectrometry); $\mathrm{N}_{2}$ : (Molecular nitrogen); NO: (Nitric oxide); OPO: (Optical parametric oscillator); OPP: (Oxidative pentose phosphate pathway); oTOF: (Orthogonal time-of-flight); PAL: (L-phenylalanine-ammonia-lyase); $\mathrm{P}_{\mathrm{B}}$ : (Sample taken from a water injection site with a blank, i.e. untreated, on the opposite side of the midvein); PC: (Principal component); PCA: (Principal component analysis); $\mathrm{P}_{\mathrm{I}}$ : (Sample taken from a water injection site with an infected, i.e. spore-injected, on the opposite side of the midvein); PLA $_{2}$ : (Phospholipase A2); PR1: (Pathogenesis-related gene 1); ROS: (Reactive oxygen species); $s / n$ : (Signal-tonoise ratio); SA: (Salicylic acid); SNN: (Samsun cultivar of Nicotiana tabacum); THB: Tetrahydrobiopterin); TOF: (Time-of-flight).

\section{Additional material}

Additional file 1 IR-LDI-oTOF MS spectra. Representative IR-LDI-oTOF mass spectra showing metabolic profiles obtained in positive and negative ion modes from an $\mathrm{I}_{\mathrm{p}}$ and a P, SNN tobacco leaf sample at 6 hpi. Presumable chemical compositions are identified for selected major ions species. A full list of detected ion signals and their tentative identities is provided in Table 1 .

Additional file 2 Unsupervised loading plots generated from the PCA Loading plots of the PCA result of Figure 4, showing all positive ions listed in Table 1; for improved clarity, nominal mass values are displayed. lons of particular interest are highlighted in boldface, including phaseic acid $(\mathrm{m} / \mathrm{z}$ 281.140) as predominantly associated with the ABA turnover, three oxylipins at $m / z 311.220,325.236$, and 361.211 , and the phenolic metabolite tyramine $(m / z 138.091)$ from the shikimic pathway. Metabolites that display the highest correlation to the biological response index (BRI), and consequently to the strength of the infection are shown in italic

Additional file $\mathbf{3}$ Validation of the BRI index. The BRI reflects the local defence response. Comparing the BRI plot and the dead cell count (DCC, \%) in SNN obtained from infected samples with different sample treatment environments on the opposite side of the midvein $\left(l_{B}\right.$ : blank; $l_{p}$ : placebo; $l_{\text {: }}$ infected). For the calculation of the BRI, 3 plant per infection times 2 leaves per plant times 3 samples per plant were used; for the DCC, 3 plants per infection times 3 leaves per plant times 14 Infection sites per plant and 17 CLSM pictures per infection site were employed.

Additional file 4 IR-LDI-OTOF MS analysis of metabolites (spatial-profile). Metabolic profiles detected by direct IR-LDI-OTOF of Nicotiana tabacum (cv. SNN) leaf samples from one single distal zone measured at 6 hpi. (A) Mass spectra were acquired from $7.5 \mathrm{~mm}$ diameter sample disks located within the infection zone. (B) Mass spectra acquired by successively moving the sample target, hence the area irradiated by the IR laser, across the imaginary border between healthy and infection zones present in one distal zone of the leaf.

\section{Competing interests}

The authors declare that they have no competing interests.

\section{Authors' contributions}

AJl conceived the study, carried out the IR-LDI MS and statistical analysis, and drafted the manuscript. JS, PB, AP, SM, ITB, FH, EW, and KD participated in the design and coordination of the study, and contributed to the manuscript. JS and PB grew the plants and bacteria, and carried out the plant infections. JS performed the death cell count analysis. AP wrote the data mining program.
SM and AJl carried out the LC-ESI MS/MS analysis of phytohormones. All authors read and approved the final manuscript.

\section{Acknowledgements}

We are grateful to Stefan Berkenkamp and Sequenom GmbH for providing use of their OTOF instrument, Matthias Schöttner for his support with the LC-ESIMS/MS phytohormone measurements, Jens Soltwisch for his support with the IR-LDI-oTOF MS measurements, Ina Schmitz-Thom for her support with the dead cell count measurements, Dr. Jutta Essmann and Dr. Aleš Svatoš for fruitful discussions and support of this project. AJl gratefully acknowledges financial support of the Alexander von Humboldt foundation.

\section{Author Details}

IInstitute of Medical Physics and Biophysics, Westfälische Wilhelms-Universität Münster, Robert-Koch-Str. 31, D-48149 Münster, Germany, Innstitute of Botany, Westfälische Wilhelms-Universität Münster, Schlossgarten 3, D-48149 Münster, Germany and ${ }^{3}$ Department of Molecular Ecology, Max Planck Institute for Chemical Ecology, Beutenberg Campus, Hans-Knöll-Str. 8, D-07745 Jena, Germany

Received: 31 March 2010 Accepted: 9 June 2010

Published: 9 June 2010

\section{References}

1. Dixon RA: Progress natural products and plant disease resistance. Nature 2001, 411:843-847.

2. Nugroho LH, Verpoorte R: Secondary metabolism in tobacco. Plant Cell Tiss Org 2002, 68:105-125.

3. Baldwin IT: An Ecologically motivated analysis of plant-herbivore interactions in native tobacco. Plant Physiol 2001, 127:1449-1458.

4. Baldwin IT, Schmelz EA: Constraints on an induced defence: the role of leaf area. Oecologia 1994, 97:424-430.

5. Halim VA, Eschen-Lippold L, Altmann S, Birschwilks M, Scheel D, Rosahl S: Salicylic acid is important for basal defence of solanum tuberosum against phytophthora infestans. Mol Plant Microbe In 2007, 20:1346-1352

6. Eyendi A, Yalpani N, Silverman P, Raskin I: Signal molecules in systemic plant resistance to pathogens and pests. Cell 1992, 70:879-886.

7. Pieterse CMJ, van Wees SCM, van Pelt JA, Knoester M, Laan R, Gerrits H, Weisbeek PJ, van Loon LC: A novel signaling pathway controlling induced systemic resistance in arabidopsis. Plant Cell 1998, 10:1571-1580.

8. Yuan $\mathrm{S}$, Lin $\mathrm{H}-\mathrm{H}$ : Role of salicylic acid in plant abiotic stress. $\mathrm{Z}$ Naturforsch C 2008, 63:313-320.

9. Alvarez ME: Salicylic acid in the machinery of hypersensitive cell death and disease resistance. Plant Mol Biol 2000, 44:429-442.

10. Vorwerk S, Schiff C, Santamaria M, Koh S, Nishimura M, Vogel J, Somerville C, Somerville S: EDR2 negatively regulates salicylic acid-based defences and cell death during powdery mildew infections of Arabidopsis thaliana. BMC Plant Biol 2007, 7:35-48.

11. Spoel SH, Koornneef A, Claessens SMC, Korzelius JP, van Pelt JA, Mueller MJ, Buchala AJ, Métraux J-P, Brown R, Kazan K, van Loon LC, Dong X, Pieterse CMJ: NPR1 modulates cross-talk between salicylate- and jasmonate-dependent defence pathways through a novel function in the cytosol. Plant Cell 2003, 15:760-770.

12. Shah J: The salicylic acid loop in plant defence. Curr Opin Plant Biol 2003, 6:365-371

13. Amirsadeghi S, Robson CA, McDonald AE, Vanlerberghe GC: Changes in plant mitochondrial electron transport alter cellular levels of reactive oxygen species and susceptibility to cell death signaling molecules. Plant Cell Physiol 2006, 47:1509-1519.

14. Zottini M, Costa A, De Michele R, Ruzzene M, Carimi F, Lo Schiavo F: Salicylic acid activates nitric oxide synthesis in Arabidopsis. J Exp Biol 2007, 58:1397-1405

15. Gould KS, Lamotte O, Klinguer A, Pugin A, Wendehenne D: Nitric oxide production in tobacco leaf cells: a generalized stress response? Plant Cell Environm 2003, 26:1851-1862.

16. Planchet E, Sonoda M, Zeier J, Keiser WM: Nitric oxide (NO) as an intermediate in the cryptogein-induced hypersensitive response - a critical re-appraisal. Plant Cell Environm 2006, 29:59-69. 
17. Scharte J, Schön H, Weis E: Photosynthesis and carbohydrate metabolism in tobacco leaves during an incompatible interaction with Phytophthora ncotianae. Plant Cell Environm 2005, 28:1421-1435.

18. Hammerschmidt R: Phytoalexins: what have we learned after 60 years? Plant J 1999, 37:285-306.

19. Van Loon LC, Van Strien EA: The families of pathogenesis-related proteins, their activities, and comparative analysis of PR-1 type proteins. Physiol Mol Plant P 1999, 55:85-97.

20. Essmann J, Schmitz-Thom I, Schön H, Sonnewald S, Weis E, Scharte J: RNA Interference-Mediated Repression of Cell Wall Invertase Impairs Defence in Source Leaves of Tobacco. Plant Physiol 2008, 147:1288-1299.

21. Huang WE, Huang L, Preston GM, Naylor M, Carr JP, Yanhong L, Singer AC, Whiteley AS, Wang H: Quantitative in situ assay of salicylic acid in tobacco leaves using a genetically modified biosensor strain of Acinetobacter sp. ADP1. Plant J 2006, 46:1073-1083.

22. Siebka K, Weis E: Assimilation images of leaves of Glechoma hederacea: analysis of non-synchronous stomata related oscillations. Planta 1995, 196:155-165.

23. Yu P, Block H, Niu Z, Doiron K: Rapid characterization of molecular chemistry, nutrient make-up and microlocation of internal seed tissue. J Synchrotron Radiat 2007, 14:382-390.

24. Wardman P: Fluorescent and luminescent probes for measurement of oxidative and nitrosative species in cells and tissues: Progress, pitfalls, and prospects. Free Radical Bio Med 2007, 43:995-1022

25. Schmelz EA, Engelberth J, Alborn HT, O'Donnell P, Sammons M, Toshima $\mathrm{H}$, Tumlinson JH: Simultaneous analysis of phytohormones, phytotoxins, and volatile organic compounds in plants. P Natl Acad Sci USA 2003, 100:10552-10557.

26. Lytovchenko A, Beleggia R, Schauer N, Isaacson T, Leuendorf JE, Hellmann $\mathrm{H}$, Rose JKC, Fernie AR: Application of GC-MS for the detection of lipophilic compounds in diverse plant tissues. Plant Methods 2009, 5:4-14.

27. Gaquerel E, Weinhold A, Baldwin IT: Molecular interactions between the specialist herbivore Manduca sexta (Lepidoptera, Sphigidae) and its natural host Nicotiana attenuata. VIII. An unbiased GCxGC-ToFMS analysis of the plant's elicited volatile emissions. Plant Physio/ 2009, 149:1408-1423.

28. Kallenbach M, Baldwin IT, Bonaventure G: A rapid and sensitive method for the simultaneous analysis of aliphatic and polar molecules containing free carboxyl groups in plant extracts by LC-MS/MS. Plant Methods 2009, 5:17-27.

29. Keinänen M, Oldham NJ, Baldwin IT: Rapid HPLC screening of jasmonate-induced increases in tobacco alkaloids, phenolics, and diterpene glycosides in Nicotiana attenuata. J Agric Food Chem 2001, 49:3553-3558.

30. Schmidt L, Hummel GM, Schöttner M, Schurr U, Walter A: Jasmonic acid does not mediate root growth responses to wounding in Arabidopsis thaliana. Plant Cell Environmen 2010, 33:104-116.

31. Kaletaş BK, van der Weil IM, Stauber J, Dekker $\sqcup$, Güzel C, Kros JM, Luider TM, Heeren RMA: Sample preparation issues for tissue imaging by imaging MS. Proteomics 2009, 9:2622-2633.

32. Fraser PD, Enfissi EMA, Goodfellow M, Eguchi T, Bramley PM: Metabolite profiling of plant carotenoids using the matrix-assisted laser desorption ionization time-of-flight mass spectrometry. Plant J 2007 49:552-564

33. Gholipour $Y$, Nonami $H$, Erra-Balsells R: Application of pressure probe and UV-MALDI-TOF MS for direct analysis of plant underivatized carbohydrates in subpicoliter single-cell cytoplasm extract. J Am SoC Mass Spectr 2008, 19:1841-1848.

34. Dreisewerd K, Lemaire R, Pohlentz G, Salzet M, Wisztorski M, Berkenkamp S, Fournier I: Molecular profiling of native and matrix-coated tissue slices from rat brain by infrared and ultraviolet laser desorption/ ionization orthogonal time-of-flight mass spectrometry. Anal Chem 2007, 79:2463-2471

35. Sun G, Yang K, Zhao Z, Guan S, Han X, Gross RW: Matrix-assisted laser desorption/ionization time-of-flight mass spectrometric analysis of cellular glycerophospholipids enabled by multiplexed solvent dependent analyte-matrix interactions. Anal Chem 2008, 80:7576-7585.

36. Zhang $\mathrm{H}, \mathrm{Cha} \mathrm{S}$, Yeung ES: Colloidal graphite-assisted laser desorption/ ionization (GALDI) MS and MSn of small molecules. 2. Direct profiling and MS imaging of small metabolites from fruits. Anal Chem 2007, 79:6575-6584.

37. Hölscher D, Shroff R, Knop K, Gottschaldt M, Crecelius A, Schneider B, Heckel DG, Schubert US, Svatos A: Matrix-free UV-laser desorption/ ionization (LDI) mass spectrometric imaging at the single-cell level: Distribution of secondary metabolites of Arabidopsis thaliana and Hypericum species. Plant J 2009, 60:907-918.

38. Li Y, Shrestha B, Vertes A: Atmospheric pressure infrared MALDI imaging mass spectrometry for plant metabolomics. Anal Chem 2008, 80:407-420

39. Shrestha B, Vertes A: In situ metabolic profiling of single cells by laser ablation electrospray ionization mass spectrometry. Anal Chem 2009, 81:8265-8271.

40. Dreisewerd K, Draude F, Kruppe S, Rohlfing A, Berkenkamp S, Pohlentz G: Molecular analysis of native tissue and whole oils by infrared laser mass spectrometry. Anal Chem 2007, 79:4514-4520.

41. Dreisewerd K, Berkenkamp S, Leisner A, Rohlfing A, Menzel C: Fundamentals of matrix-assisted laser desorption/ionization mass spectrometry with pulsed infrared lasers. Int J Mass Spectrom 2003, 226:189-209.

42. Trim PJ, Atkinson SJ, Princivalle AP, Marshall PS, West A, Clench MR: Matrixassisted laser desorption/ionisation mass spectrometry imaging of lipids in rat brain tissue with integrated unsupervised and supervised multivariant statistical analysis. Rapid Commun Mass Spectrom 2008, 22:1503-1509.

43. Henderson A, Fletcher JS, Vickerman JC: A comparison of PCA and MAF for ToF-SIMS image interpretation. Surf Interface Anal 2009, 41:666-674.

44. Loboda AV, Ackloo S, Chernushevich IV: A high-performance matrixassisted laser desorption/ionization orthogonal time-of-flight mass spectrometer with collisional cooling. Rapid Commun Mass Spectrom 2003, 17:2508-2516

45. Krutchinsky AN, Loboda AV, Spicer VL, Dworschak R, Ens W, Standing KG: Orthogonal injection of matrix-assisted laser desorption/ionization ions into a time-of-flight spectrometer through a collisional damping interface. Rapid Commun Mass Spectrom 1998, 12:508-518.

46. Soltwisch J, Souady J, Berkenkamp S, Dreisewerd K: Effect of gas pressure and gas type on the fragmentation of peptide and oligosaccharide ions generated in an elevated pressure UV/IR-MALDI ion source coupled to an orthogonal time-of-flight mass spectrometer. Anal Chem 2009, 81:2921-2934

47. Corpas FJ, Barroso JB, Carreras A, Valderrama R, alma JM, Leon AM, Sandalio LM, del Rio LA: Constitutive arginine-dependant nitric oxide synthase activity in different organs of pea seedlings during plant development. Planta 2006, 224:246-254.

48. Wendehammer D, Durner J, Klessig DF: Nitric oxide: a new player in plant signaling and defence responses. Curr Opin Plant Biol 2004 7:449-455

49. Igarashi K, Kashiwagi K: Modulation of cellular function by polyamines. Int J Biochem Cell Biol 2010, 42:39-51.

50. Kidd SK, Melillo AA, Lu R-H, Reed DG, Kuno N, Uchida K, Furuya M, Jelesko $J G$ : The $A$ and $B$ loci in tobacco regulate a network of stress response genes, few of which are associated with nicotine biosynthesis. Plant Molecul Biol 2006, 60:699-716

51. Shetty P, Atallah MT, Shetty K: Stimulation of total phenolics, L-DOPA and antioxidant activity through proline-linked pentose phosphate pathway in response to proline and its analogue in germinating fava beans (Vicia faba). Process Biochem 2003, 38:1707-1717.

52. Mueller MJ: Archetype signals in plants: the phytoprostanes. Curr Opin Plant Biol 2004, 7:441-448.

53. Mueller MJ, Berger S: Reactive electrophilic oxylipins: pattern recognition and signalling. Phytochemistry 2009, 70:1511-1521

54. Shah J: Lipids, Lipases and Lipid-modifying enzymes in plant disease resistance. Annu Rev Phytopathol 2005, 43:229-260.

55. Li X-C, Joshi AS, EISohly HN, Khan SI, Jacob MR, Zhang Z, Khan IA, Ferreira D, Walker D, Walker LA, Broedel SE, Raulli RE, Cihlar RL: Fatty acid synthase inhibitors from plants: isolation, structure elucidation, and SAR studies. J Nat Prod 2002, 65:1909-1914

56. Göbel C, Feussner I, Rosahl S: Lipid peroxidation during the hypersensitive response in potato in the absence of 9-lipoxygenases. J Biol Chem 2003, 278:52834-52840.

57. Montillet J-L, Chamnongpol S, Rusterucci C, Dat J, van de Cotte B, Agnel J$P$, Battesti $C$, Inze D, van Breusegem F, Triantaphylidès C: Fatty Acid 

in tobacco leaves. Plant Physiol 2005, 138:1516-1526.

58. Cacas J-L, Vailleau F, Devoine C, Ennar N, Agnel J-P, Tronchet M, Ponchet $M$, Blein J-P, Roby D, Triantaphylidès C, Montillet J-C: The combined action of 9 lipoxygenase and galactolipase is sufficient to bring about programmed cell death during tobacco hypersensitive response. Plant Cell Environmen 2005, 28:1367-1378.

59. Montillet J-L, Cacas J-L, Garnier L, Montané M-H, Douki T, Bessoule J-J, Polkowska-Kowalczyk L, Maciejewska U, Agnel J-P, Vial A, Triantaphylidès C: The upstream oxylipin profile of Arabidopsis thaliana: a tool to scan for oxidative stresses. Plant $J$ 2004, 40:439-451.

60. Véronési C, Rickauer M, Fournier J, Pouénat M-L, Esquerré-Tugayé M-T: Lipoxygenase gene expression in the tobacco-phytophthora parasitica nicotianae interaction. Plant Physiol 1996, 112:997-1004

61. Munnik T, Irvine RF, Musgrave A: Phospholipid signalling in plants. Biochim Biophys Acta 1998, 1389:222-272.

62. Świątek A, Lenjou M, van Bockstaele D, Inzé D, van Onckelen H: Differential effect of jasmonic acid and abscisic acid on cell cycle progression in tobacco BY-2 cells. Plant Physiol 2002, 128:201-211.

63. Seo M, Koshiba T: Complex regulation of ABA biosynthesis in plants. Trends Plant Sci 2002, 7:41-48.

64. Steadman JR, Sequeira L: Abscisic acid in tobacco plants. Plant Physiol 1970, 45:691-697.

65. Ton J, Flors V, Mauch-Mani B: The multifaceted role of ABA in disease resistance. Trends Plant Sci 2009, 14:310-317.

66. Cheng W-H, Endo A, Zhou L, Penney J, Chen H-C, Arroyo A, Leon P, Nambara E, Asami T, Seo M, Koshiba T, Sheen J: A unique short-chain dehydrogenase/reductase in Arabidopsis glucose signaling and abscisic acid biosynthesis and functions. Plant Cell 2002, 14:2723-2743.

67. Schmidt K, Plugmacher M, Klages S, Maeser A, Mock A, Stahl DJ: Accumulation of the hormone abscisic acid (ABA) at the infection site of the fungus Cercospora beticola supports the role of $A B A$ as a repressor of plant defence in sugar beet. Mol Plant Pathol 2008, 9:661-673.

68. Nambara E, Marion-Poll : Absicic acid biosíntesis and catabolism. A Annu Rev Plant Biol 2005, 56:165-185.

69. Cutler AJ, Krochko JE: Formation and breakdown of ABA. Trends Plant Sci 1999, 4:472-478.

70. Kenton P, Mur LAJ, Atzorn R, Wasternack C, Draper J: (-)-Jasmonic acid accumulation in tobacco hypersensitive response lesions. Mol Plant Microbe In 1999, 12:74-78.

71. Kaiser AE, Gottwald AM, Wiersch CS, Maier WA, Seitz HM: Spermidine metabolism in parasitic protozoa - a comparison to the situation in prokaryotes, viruses, plants and fungi. Folia Parasit 2003, 50:3-8.

72. Stork W, Diezel C, Halitschke R, Galis I, Baldwin IT: An ecological analysis of the herbivory-elicited JA burst and its metabolism: plant memory processes and predictions of the moving target model. PLOS One 2009, 4:e4697-e4611.

doi: 10.1186/1746-4811-6-14

Cite this article as: Ibáñez et al., Rapid metabolic profiling of Nicotiana tabacum defence responses against Phytophthora nicotianae using direct infrared laser desorption ionization mass spectrometry and principal component analysis Plant Methods 2010, 6:14

Submit your next manuscript to BioMed Centra and take full advantage of:

- Convenient online submission

- Thorough peer review

- No space constraints or color figure charges

- Immediate publication on acceptance

- Inclusion in PubMed, CAS, Scopus and Google Scholar

- Research which is freely available for redistribution

Submit your manuscript at www.biomedcentral.com/submit
C BioMed Central 